Article

\title{
Research on Spatial Correlations and Influencing Factors of Logistics Industry Development Level
}

\author{
Xinbao Tian * and Meirong Zhang \\ School of economics and management, Shanxi University, Taiyuan 030006, China; qxzhang@sxu.edu.cn \\ * Correspondence: tianxinb@sxu.edu.cn.com; Tel.: +86-351-701-0500
}

Received: 14 February 2019; Accepted: 28 February 2019; Published: 5 March 2019

\begin{abstract}
The logistics industry plays a greater role in the sustainable development of regional economies. The development of the logistics industry between regions is not independent, and there is a spatial correlation due to the existence of spatial spillover effect or spatial expansion among regions. This paper uses the method of entropy weight to evaluate the development level of the logistics industry in 31 provinces in China. On this basis, Moran's index (Moran's I), Moran's I scatter plot, and local indicators of spatial association (LISA) agglomeration plot are used to analyze the overall and local spatial agglomeration characteristics of the logistics industry. Four main factors affecting the spatial relationship of the logistics industry are analyzed by choosing the fixed effect of the spatial error model. We find that: (i) There is spatial agglomeration effect in the development level of the logistics industry from the overall perspective; (ii) regional differentiation of the spatial agglomeration effect of logistics industry development level is obvious from the local perspective; and (iii) the influence of human resource factors on the spatial relationship of logistics development level is declining.
\end{abstract}

Keywords: logistics industry; Moran's index; spatial correlation

\section{Introduction}

The logistics industry has increasingly shown its important role and strategic position in regional economic growth. The logistics industry promotes the upgrading of regional industrial structures, to a certain extent, by improving the efficiency of economic activities, reducing transaction costs between enterprises, and providing corresponding logistics information, thus promoting the sustainable development of the regional economy. The logistics industry in China has achieved rapid development in recent years. During 2001 and 2016, the output value of the logistics industry in China increased from 687.03 billion yuan to 3.335 trillion yuan, an increase of $385.5 \%$; the number of employees in the logistics industry increased from 5,937,664 to $8,495,076$, an increase of $43.07 \%$; the total length of railway, highway, inland river, civil aviation, and pipeline transportation lines increased from 3,932,612 km to $4,947,355 \mathrm{~km}$, an increase of $25.8 \%$; the volume of express business increased from $126,527,000$ to $31,283,151,090$, an increase of 246.3 times [1,2]. During this period, the Chinese government had put forward a series of national economic strategies, such as "Western development", "Revitalization of Northeast China", "Integration of Yangtze River Delta, Pearl River Delta", "Coordinated development of Beijing, Tianjin, and Hebei province", and "One belt and One road", which effectively promoted the development of regional economies. Logistics has played a more important role in regional economic development, as the logistics industry has a strong driving effect, not only to the relevant industries, but also to accelerate the flow of resources in the region, as well as regional exchanges and economic cooperation. There exists a phenomenon of agglomeration of the logistics industry among regions, which is caused by regional spatial correlations. The reason why the regional spatial relationship of the logistics industry is becoming closer and closer is mainly due to the following reasons: (i) The degree 
of regional economic cooperation has expanded. For the balanced development of regional economies, the government has implemented a series of related policies, such as the upgraded version of the Northeast Revitalization Plan, which is to form a one-to-one support mechanism between developed regions and Northeast regions. Regional economic development needs to realize the rational flow and optimization of natural resources and social resources, which mainly depends on the function of logistics. However, the demand and supply of resources in different economic regions are significantly different, which leads to the spatial differentiation of the logistics industry and provides conditions for regional cooperation of logistics. (ii) There are obvious differences in logistics demand among regions. The demand for production and consumption between regions cannot be fully supplied entirely locally, so it must be supplied by logistics outside the region, which forms the logistics links between regions. (iii) The function of logistics resources must be planned effectively. Logistics infrastructure, such as railways, highways, ports, and transportation hubs, is often planned and laid out across regions, which requires the development of logistics in different regions to be linked by infrastructure. On the one hand, it breaks through the regional restrictions of logistics, while on the other hand, it fully improves the utilization rate of logistics infrastructure and avoids the inefficient use of resources. The significance of studying the spatial correlation of the logistics industry lies in that in the process of regional economic development, each region considers the development of the logistics industry more from the perspective of its own region, and through the study of the spatial correlation of the logistics industry, each region can pay more attention to regional cooperation in the process of development, thus providing a strong guarantee for the sustainable development of regional economies.

Research on the logistics industry is currently being carried out and its perspectives and methods are expanding. The role of the logistics industry in regional economic development is already well known, but there is no consensus on how to measure the logistics industry. There are two main measurement approaches in the current empirical literature. One is the study on the competitiveness of the logistics industry. Yeo et al. used the method of fuzzy comprehensive evaluation to evaluate the competitiveness of the logistics industry of six container ports in China, such as Hong Kong and Shanghai [3]. Some scholars also used regression analysis to study the logistics industry. Mothilals et al. used multiple regression analysis to evaluate the competitiveness of its logistics industry by comparing India, the United States, and Hong Kong [4]. Tang et al. used the fixed effect regression model and stepwise regression econometric model to measure the competitiveness of the logistics industry in 11 eastern provinces [5]. Some scholars used entropy method to determine entropy first, and then combined other methods to study the competitiveness of the logistics industry [6-9]. In addition, Wang et al. used the method of factor analysis to evaluate the competitiveness and potential of the logistics industry in eight inland node cities based on the idea of dimensionality reduction and simplification of index by factor analysis and the characteristics of solving dimensionless problems of the index [10]. Factor analysis, clustering statistics, and fuzzy approximation ideal ranking method were also used to evaluate the competitiveness of the logistics industry [11-13]. The other is the study of the efficiency of the logistics industry. Scholars mostly used data envelopment analysis (DEA) and stochastic frontier analysis (SFA) to study the efficiency of the logistics industry. Sun et al. established the input-output index system and estimated the logistics efficiency of the three northeastern provinces of China by three-stage DEA [14]. Markovits-Somogyi used the method of DEA-PC (pairwise comparison) to evaluate the efficiency of the logistics industry in 29 European countries and proved the superiority of this method [15]. Chen et al. used the method of super-efficiency data envelopment analysis (SE-DEA) to measure the comprehensive technical efficiency and pure technical efficiency of the logistics industry in 31 provinces of China, decomposed the scale efficiency, and analyzed the difference of its efficiency value [16]. Fans used the SFA method of Cobb-Douglas production function to study the efficiency of the logistics industry in national circulation node cities [17]. Herein, we adopt the establishment of the evaluation index system to evaluate the development level of the logistics industry. 
Most previous studies have considered each region as an independent system without considering the possible correlation effects. If the logistics industry is indeed spatially correlated in China, then neglecting such spatial effects in economic models will result in biased or inconsistent parameter estimates. Therefore, it is necessary to study spatial correlation in the logistics industry. Some scholars have indeed studied logistics from the perspective of spatial correlation. The research on spatial correlation of logistics mainly includes three aspects, as follows:

(i) Research on facilities and activity space layout of the logistics industry. Dablanc et al. put forward the concept of "logistics sprawl", which was defined as "the spatial deconcentration of logistics facilities and distribution centers in metropolitan areas" [18]. The result of logistics sprawl was longer truck trip distances, which exacerbated the negative externalities. Those outward migrations of logistics facilities had not occurred for their own sake. The spatial transformation of logistics land use was prompted by the structural changes in logistics systems. Hesse and Rodrigue argued that the evolution of logistics that integrated different activities in the supply chain, such as "supplying, warehousing, production, and distribution functions", made possible by the innovations in information and communication technology (ICT), have reshaped freight transportation systems since the 1960s [19]. One of the key changes was the emergence of pull-logistics that had contributed to the significant reduction in cycle time and inventory cost. As a result, larger facilities with high throughput were becoming increasingly more desirable or even essential for pull-logistics operations [20-22]. Dablanc chose Atlanta, the largest metropolitan area in the United States, as the research object from the perspective of the spatial distribution of cargo transportation and logistics activities, and pointed out that the metropolitan logistics facilities and distribution centers were in a state of disorderly expansion in space, while logistics activities were concentrated in metropolitan areas [23]. Cidell used Gini coefficient as an index to measure the degree of concentration and made a spatial analysis of warehousing and freight transport activities in metropolitan areas of the United States since the 1980s. The results showed that the scope of work of warehousing and transportation enterprises was decentralized in space, and highlighted the trend of gradual outward development from urban centers, which is conducive to close cooperation with metropolitan areas [24].

(ii) Research on the spatial distribution of logistics from the perspective of enterprises. John et al. surveyed the geographical changes of warehouses in the United States between 1998 and 2005 [25]. After understanding the extent of warehousing expansion, they pointed out that the increase in the number of raw materials, semi-finished products, and finished products increased the importance of warehouses in the logistics process. As a result, the layout planning of enterprises changed significantly and enterprises gradually moved to the suburbs and chose locations where transportation was convenient. Zhang et al. used the methods of nuclear density analysis and hot spot analysis to study the spatial distribution characteristics of logistics enterprises in Beijing-Tianjin-Hebei urban agglomeration in 1995, 2005, and 2015, and used the geographic weighted regression model (GWR) to analyze the influencing factors of the evolution of logistics enterprises [26].

(iii) Research on spatial distribution of the logistics industry. On the one hand, scholars discussed the spatial distribution, network structure, evolution mechanism, and driving factors of the logistics industry [27-29]. For example, Shen et al. used location Gini coefficient and location entropy method to analyze the spatial distribution and evolution characteristics of the logistics industry in the Yangtze River Delta. It was found that the spatial agglomeration characteristics were obvious and the corridor effect was prominent [30]. On the other hand, scholars carried out research on spatial heterogeneity between the logistics industry and the regional economy. Cheng et al. explored the relevance of the logistics industry in the Yangtze River Economic Zone and its impact on economic development, revealing the regional differences of correlation degree and the spatial differences of impact situation [31]. Jing et al. took Heilongjiang, Jilin, and Liaoning provinces as research objects, chose three-year city-level data, used ArcGIS and GeoDa spatial measurement software to analyze the spatial distribution and structure characteristics of logistics and regional economies, and explained the heterogeneity of logistics and economy in space [32]. 
We can see that the existing relating literature mainly focuses on logistics spatial relations from the perspective of industrial function and research on logistics function layout at the enterprise level. Although there are some research studies from the regional perspective to analyze the characteristics of spatial relationship of the logistics industry, most were more from the perspective of logistics and regional economy, not from the perspective of comprehensive analysis of the spatial characteristics of the logistics industry itself. In order to reveal the spatial relationship of the logistics industry caused by its own factors, this paper will do the following work:

(i) Use entropy weight method to determine the comprehensive level value of the logistics industry. The reason for choosing Entropy Weight Method is that it overcomes the subjective shortcomings of Analytic Hierarchy Process (AHP) and makes the calculated weights more scientific and easier to be understood and accepted. Data of evaluation indicators came from the China Statistical Yearbook. The research period is set from 2008 to 2016.

(ii) Use Moran's I and Moran's I scatter plots to analyze the spatial correlation of the logistics industry, overall and locally. In the local analysis, 31 provinces in 2008, 2012, and 2016 are selected for spatial correlation analysis, and the heterogeneity and homogeneity of logistics development level in 31 provinces are estimated.

(iii) Use Spatial lag model (SLM) and spatial error model (SEM) to analyze the influencing factors of spatial relationship in logistics industry. Herein, logistics infrastructure factors, economic development factors, information factors, and human resource factors are selected as influencing factors for analysis.

The remainder of this paper is structured as follows. Section 2 evaluates the development level of the logistics industry. Section 3 analyses the spatial characteristics of the development of the logistics industry. Section 4 is the quantitative analysis of the influencing factors of the spatial relationship of the logistics industry. Section 5 presents conclusions, implications, and limitations.

\section{Evaluation of the Development Level of the Logistics Industry}

\subsection{Evaluation Index System}

The development of the logistics industry can be evaluated from multiple dimensions. In this paper, nine indicators will be selected from three aspects-the scale of logistics transportation, the level of economic development, and the logistics infrastructure and personnel-to construct the evaluation index system of logistics industry development level, as shown in Figure 1.

In the process of index selection, on the one hand, the characteristics of logistics industry development are fully considered, while on the other hand, the representativeness, economy, and accessibility of data are also taken into account. In the process of establishing the primary indicators, it evaluates the development of the logistics industry from the perspective of quantity firstly, and selects the scale indicators of logistics transportation as secondary indicators. There are mainly two types of transportation, namely, freight and passenger transportation. Therefore, the scale of logistics transportation is reflected by freight volume (10,000 tons), passenger volume (10,000 persons), freight turnover volume (100 million tons $\mathrm{km})$, and passenger turnover volume (100 million person $\mathrm{km})$. Secondly, it evaluates the development of the logistics industry from the perspective of economy. The development of the logistics industry itself and the impact of the external economic environment are both considered. The level of economic development is reflected by regional transportation, warehousing and postal industry output value (100 million yuan), regional gross product (100 million yuan), and per capita gross product (yuan). Thirdly, it evaluates the development of the logistics industry from the perspective of industry development conditions. Logistics infrastructure chooses the total mileage of railways, highways, and inland waterways as the length of transport routes $(\mathrm{km})$, and the personnel choose the number of people employed in transportation, warehousing, and the postal industry as the human resources data to reflect. 


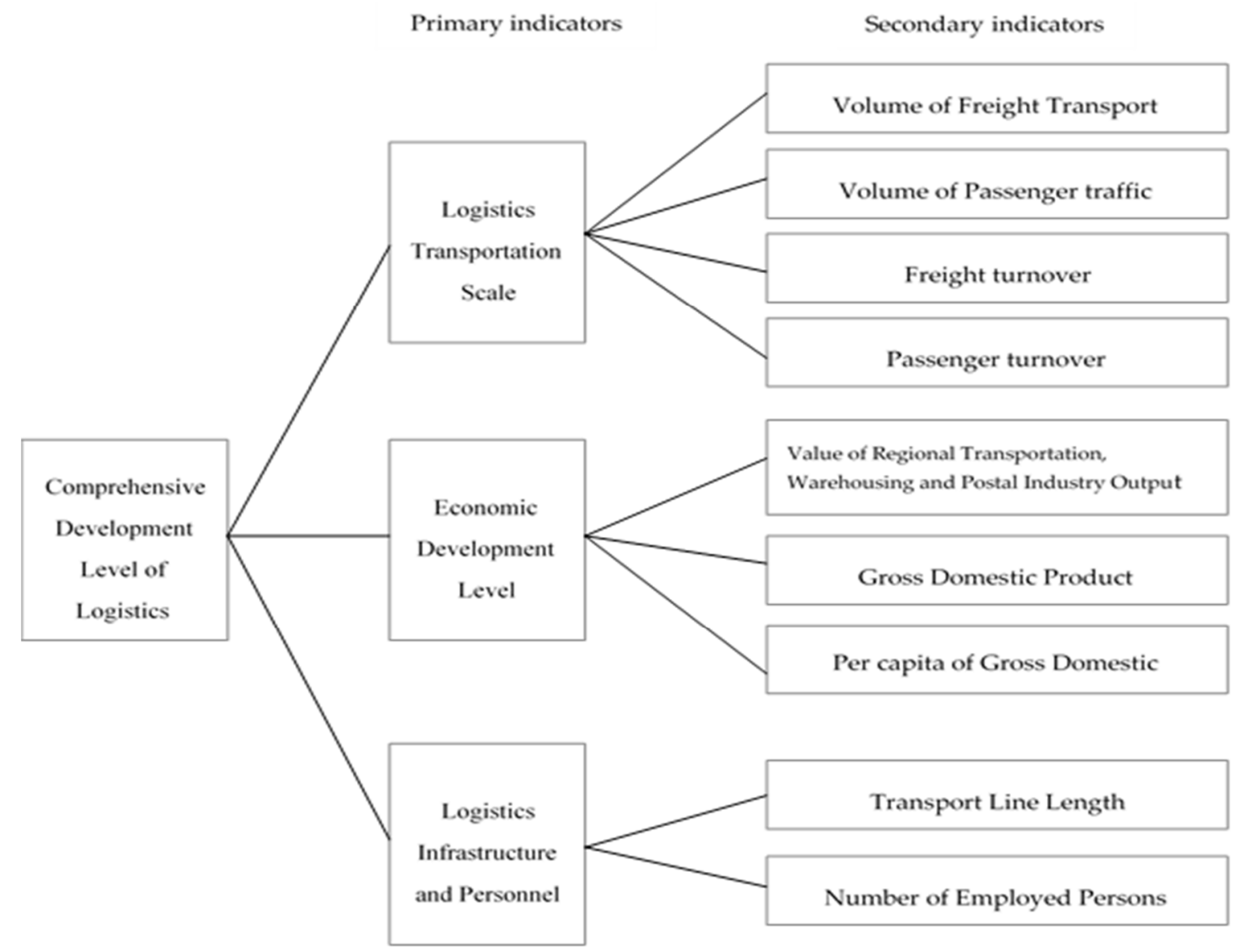

Figure 1. Index system of comprehensive level of the logistics industry.

\subsection{Evaluation of the Development Level of the Logistics Industry}

Most studies used AHP and the entropy weight method to determine the weight of indicators. However, due to the strong subjectivity of AHP, different experts have different opinions on the relative importance of indicators. Entropy weight method overcomes subjectivity, making the calculated weights more scientific and easier to understand and accept. Therefore, this paper uses the method of entropy weight to determine the comprehensive level value of the logistics industry. The specific process of calculating the weights of secondary indicators is as follows.

(i) Calculate the proportion $\mathrm{P}_{i j}$ of the index value in the $i$ year under item $j$. The formula is as follows:

$$
\mathrm{p}_{i j}=\frac{y_{i j}}{\sum_{i=1}^{m} y_{i j}}
$$

(ii) Determine the information entropy weight $\mathrm{e}_{j}$ of item $j$ index; the larger the information entropy, the smaller the information contained in the index, and the smaller the final weight value of the index. The formula is as follows:

$$
\mathbf{e}_{j}=\frac{-\sum_{i=1}^{m} p_{i j} * \ln \left(p_{i j}\right)}{\ln (m)}
$$

where $m$ is the number of study areas

(iii) Calculate the utility value $d_{j}$ of item $j$. The formula is as follows:

$$
\mathrm{d}_{\mathrm{j}}=1-\mathrm{e}_{\mathrm{j}}
$$


(iv) Calculate the weight value of index $\mathrm{j}$. The formula is as follows:

$$
w_{j}=\frac{d_{j}}{\sum d_{j}}
$$

Above is the method of calculating the weights of secondary indicators. The process of calculating the comprehensive level value of the logistics industry is as follows:

(i) Standardize data as $\mathrm{q}_{j}$. The formula is as follows:

$$
\mathrm{q}_{j}=\frac{y_{j}-\min \left(y_{i j}\right)}{\max \left(y_{i j}\right)-\min \left(y_{i j}\right)}
$$

(ii) Calculate the comprehensive level value $R_{j}$ of logistics industry. The formula is as follows:

$$
R_{j}=q_{j} * w_{j}
$$

The weights of secondary indicators of 31 provinces from 2008 to 2016 are obtained by using the method of entropy weight (see Table 1). The weights of primary indicators can be seen in Table 2.

Then, we can get the comprehensive development level of the logistics industry from 2008 to 2016 (see Table 3). It can be seen from Table 4 that the level of logistics development varies from 2008 to 2016. Overall, due to various factors, the comprehensive level of logistics in western provinces lags behind the central and Eastern regions, but the level of logistics development is growing faster. Guangdong Province has always ranked first in the value of its comprehensive logistics development level for its location advantages. Shandong, Jiangsu, Zhejiang, Hebei, and other provinces have formed a unique three-dimensional transportation network by virtue of the combination of dense ports, highways, railways, shipping, and other multi-mode transport. At the same time, they are also radiated and driven by the Beijing-Tianjin-Hebei Economic Belt and the Yangtze River Delta Economic Belt. They have effectively promoted the development of the logistics industry, and have strong comprehensive logistics capacity. They rank first in the development of logistics in the provinces of the country. For the Western region, such as Shaanxi, Qinghai, Guizhou, Ningxia, and other provinces, the level of logistics development has been at a low level due to the comprehensive influence of weak infrastructure and lack of location advantages. 
Table 1. Weights of secondary indicators from 2008 to 2016.

\begin{tabular}{|c|c|c|c|c|c|c|c|c|c|}
\hline Year & $\begin{array}{l}\text { Volume of } \\
\text { Freight } \\
\text { Transport }\end{array}$ & $\begin{array}{c}\text { Volume of } \\
\text { Passenger } \\
\text { Traffic }\end{array}$ & $\begin{array}{l}\text { Freight } \\
\text { Turnover }\end{array}$ & $\begin{array}{c}\text { Passenger } \\
\text { Turnover }\end{array}$ & $\begin{array}{c}\text { Value of } \\
\text { Regional T, } \\
\text { W, P, Output }\end{array}$ & $\begin{array}{c}\text { Gross } \\
\text { Domestic } \\
\text { Product }\end{array}$ & $\begin{array}{c}\text { Per capita of } \\
\text { Gross Domestic } \\
\text { Product }\end{array}$ & $\begin{array}{c}\text { Transport } \\
\text { Line Length }\end{array}$ & $\begin{array}{c}\text { Number of } \\
\text { Employed } \\
\text { Persons }\end{array}$ \\
\hline 2008 & 0.101 & 0.168 & 0.168 & 0.107 & 0.119 & 0.130 & 0.062 & 0.070 & 0.075 \\
\hline 2009 & 0.109 & 0.154 & 0.168 & 0.112 & 0.114 & 0.130 & 0.062 & 0.072 & 0.080 \\
\hline 2010 & 0.110 & 0.156 & 0.174 & 0.115 & 0.115 & 0.126 & 0.050 & 0.072 & 0.082 \\
\hline 2011 & 0.110 & 0.161 & 0.168 & 0.117 & 0.118 & 0.121 & 0.044 & 0.073 & 0.089 \\
\hline 2012 & 0.114 & 0.169 & 0.159 & 0.124 & 0.118 & 0.120 & 0.041 & 0.074 & 0.081 \\
\hline 2013 & 0.110 & 0.114 & 0.149 & 0.101 & 0.114 & 0.115 & 0.037 & 0.070 & 0.190 \\
\hline 2014 & 0.106 & 0.116 & 0.158 & 0.110 & 0.106 & 0.114 & 0.131 & 0.069 & 0.091 \\
\hline 2015 & 0.113 & 0.116 & 0.185 & 0.111 & 0.124 & 0.132 & 0.041 & 0.078 & 0.100 \\
\hline 2016 & 0.104 & 0.103 & 0.180 & 0.102 & 0.108 & 0.122 & 0.123 & 0.070 & 0.088 \\
\hline
\end{tabular}

Note: Value of Regional T, W, P, Output represents Value of Regional Transportation, Warehousing, and Postal Industry Output. 
Table 2. Weights of primary indicators from 2008 to 2016.

\begin{tabular}{cccc}
\hline Year & $\begin{array}{c}\text { Logistics } \\
\text { Transportation Scale }\end{array}$ & $\begin{array}{c}\text { Economic } \\
\text { Development Level }\end{array}$ & $\begin{array}{c}\text { Logistics Infrastructure } \\
\text { and Personnel }\end{array}$ \\
\hline 2008 & 0.544 & 0.311 & 0.145 \\
2009 & 0.543 & 0.306 & 0.151 \\
2010 & 0.554 & 0.292 & 0.154 \\
2011 & 0.556 & 0.283 & 0.161 \\
2012 & 0.566 & 0.279 & 0.155 \\
2013 & 0.473 & 0.266 & 0.260 \\
2014 & 0.490 & 0.350 & 0.160 \\
2015 & 0.525 & 0.297 & 0.177 \\
2016 & 0.489 & 0.353 & 0.158 \\
\hline
\end{tabular}

Table 3. Value of Comprehensive Development Level of Logistics Industry from 2008 to 2016.

\begin{tabular}{|c|c|c|c|c|c|c|c|c|}
\hline Province & 2008 & 2009 & 2011 & 2012 & 2013 & 2014 & 2015 & 2016 \\
\hline Beijing & 0.265 & 0.285 & 0.282 & 0.263 & 0.233 & 0.229 & 0.277 & 0.236 \\
\hline Tianjin & 0.161 & 0.263 & 0.232 & 0.209 & 0.173 & 0.157 & 0.184 & 0.149 \\
\hline Hebei & 0.422 & 0.455 & 0.477 & 0.479 & 0.505 & 0.471 & 0.534 & 0.466 \\
\hline Liaoning & 0.392 & 0.416 & 0.421 & 0.427 & 0.480 & 0.445 & 0.507 & 0.406 \\
\hline Shanghai & 0.407 & 0.404 & 0.389 & 0.367 & 0.341 & 0.353 & 0.429 & 0.369 \\
\hline Jiangsu & 0.552 & 0.593 & 0.617 & 0.622 & 0.659 & 0.623 & 0.722 & 0.625 \\
\hline Zhejiang & 0.479 & 0.492 & 0.496 & 0.479 & 0.497 & 0.463 & 0.557 & 0.485 \\
\hline Fujian & 0.249 & 0.257 & 0.255 & 0.256 & 0.281 & 0.281 & 0.348 & 0.312 \\
\hline Shandong & 0.734 & 0.775 & 0.719 & 0.701 & 0.604 & 0.545 & 0.644 & 0.581 \\
\hline Guangdong & 0.756 & 0.781 & 0.799 & 0.835 & 0.764 & 0.805 & 0.897 & 0.866 \\
\hline Hainan & 0.053 & 0.058 & 0.064 & 0.061 & 0.044 & 0.051 & 0.062 & 0.053 \\
\hline Shanxi & 0.243 & 0.230 & 0.235 & 0.231 & 0.408 & 0.217 & 0.254 & 0.217 \\
\hline Jilin & 0.167 & 0.172 & 0.169 & 0.169 & 0.168 & 0.151 & 0.180 & 0.155 \\
\hline Heilongjiang & 0.225 & 0.224 & 0.215 & 0.208 & 0.201 & 0.324 & 0.228 & 0.194 \\
\hline Anhui & 0.388 & 0.406 & 0.422 & 0.448 & 0.531 & 0.503 & 0.506 & 0.450 \\
\hline Jiangxi & 0.238 & 0.244 & 0.240 & 0.242 & 0.281 & 0.267 & 0.313 & 0.281 \\
\hline Henan & 0.502 & 0.516 & 0.521 & 0.533 & 0.504 & 0.511 & 0.596 & 0.655 \\
\hline Hubei & 0.328 & 0.341 & 0.345 & 0.351 & 0.397 & 0.390 & 0.483 & 0.432 \\
\hline Hunan & 0.360 & 0.385 & 0.403 & 0.407 & 0.475 & 0.443 & 0.507 & 0.440 \\
\hline Sichuan & 0.383 & 0.394 & 0.395 & 0.400 & 0.389 & 0.395 & 0.482 & 0.425 \\
\hline Guizhou & 0.126 & 0.155 & 0.162 & 0.167 & 0.343 & 0.210 & 0.266 & 0.242 \\
\hline Yunnan & 0.171 & 0.169 & 0.168 & 0.167 & 0.214 & 0.185 & 0.227 & 0.202 \\
\hline Tibet & 0.017 & 0.016 & 0.015 & 0.015 & 0.024 & 0.015 & 0.020 & 0.017 \\
\hline Shaanxi & 0.237 & 0.259 & 0.267 & 0.266 & 0.277 & 0.278 & 0.324 & 0.288 \\
\hline Gansu & 0.136 & 0.141 & 0.142 & 0.144 & 0.147 & 0.147 & 0.176 & 0.156 \\
\hline Qinghai & 0.040 & 0.041 & 0.044 & 0.040 & 0.058 & 0.039 & 0.046 & 0.043 \\
\hline Ningxia & 0.043 & 0.050 & 0.055 & 0.059 & 0.060 & 0.047 & 0.060 & 0.050 \\
\hline Xinjiang & 0.156 & 0.150 & 0.149 & 0.160 & 0.172 & 0.170 & 0.201 & 0.171 \\
\hline Inner Mongolia & 0.260 & 0.291 & 0.301 & 0.306 & 0.270 & 0.265 & 0.296 & 0.261 \\
\hline Guangxi & 0.226 & 0.237 & 0.255 & 0.261 & 0.244 & 0.237 & 0.289 & 0.258 \\
\hline Chongqing & 0.194 & 0.209 & 0.225 & 0.221 & 0.217 & 0.221 & 0.278 & 0.246 \\
\hline
\end{tabular}

Table 4. Overall Moran's Index of Logistics Development Level.

\begin{tabular}{cccccccccc}
\hline & $\mathbf{2 0 0 8}$ & $\mathbf{2 0 0 9}$ & $\mathbf{2 0 1 0}$ & $\mathbf{2 0 1 1}$ & $\mathbf{2 0 1 2}$ & $\mathbf{2 0 1 3}$ & $\mathbf{2 0 1 4}$ & $\mathbf{2 0 1 5}$ & $\mathbf{2 0 1 6}$ \\
\hline Moran's I & 0.3124 & 0.3221 & 0.3300 & 0.3185 & 0.2990 & 0.3382 & 0.2831 & 0.3083 & 0.2947 \\
Z & 3.0684 & 3.1208 & 3.2063 & 3.0928 & 3.1276 & 3.29 & 2.7166 & 2.9398 & 2.9317 \\
P & 0.009 & 0.006 & 0.004 & 0.007 & 0.004 & 0.002 & 0.008 & 0.006 & 0.003 \\
\hline
\end{tabular}




\section{Spatial Agglomeration Characteristics of Logistics Industry Development Level}

\subsection{Overall Spatial Agglomeration Characteristics of Logistics Industry Development}

In order to understand the spatial relationship of logistics development more intuitively, the overall Moran's index value, probability $\mathrm{P}$ value, and $\mathrm{Z}$ value reflecting the level of spatial relationship of logistics development from 2008 to 2016 are calculated through the overall autocorrelation analysis of 31 provinces in China by the spatial measurement software Geoda, as shown in Table 4 and Figure 2.

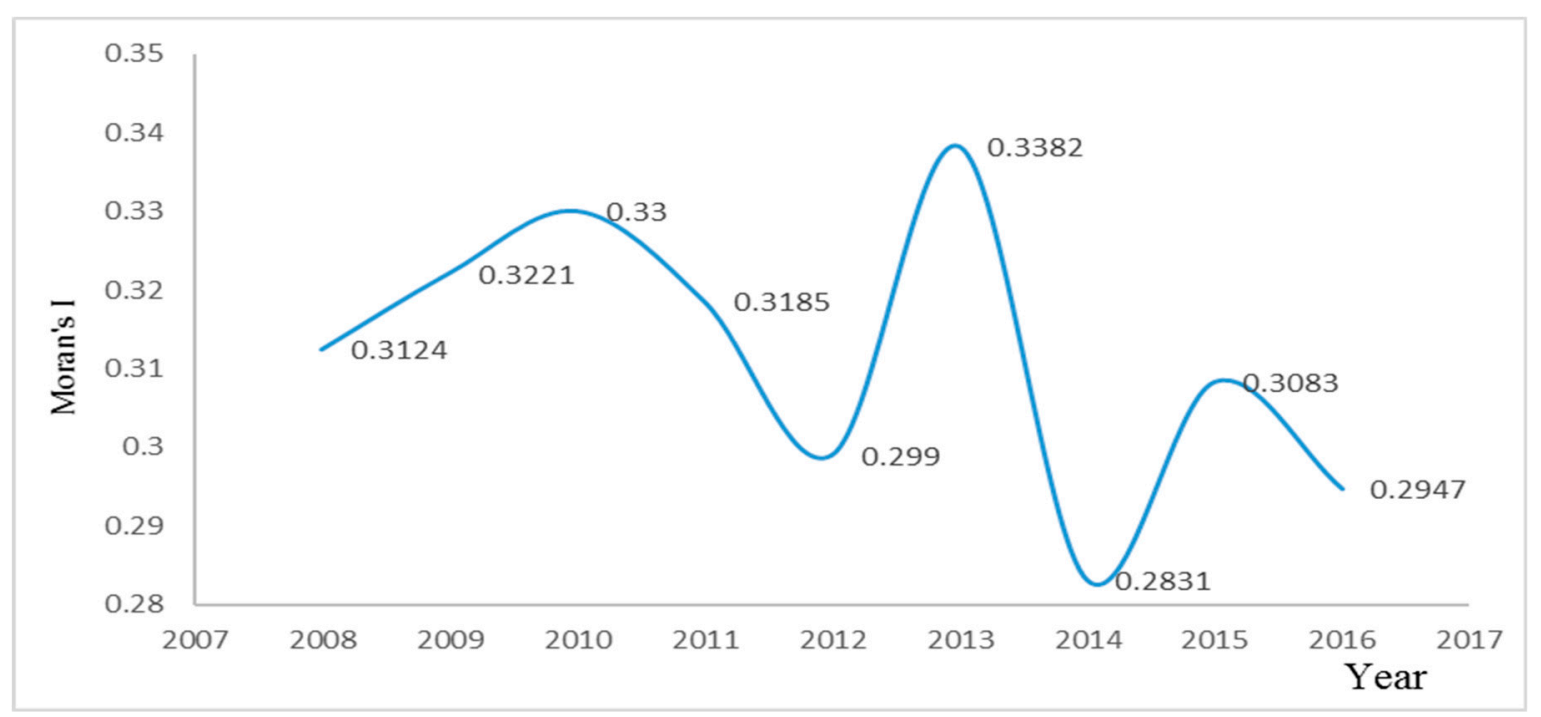

Figure 2. Overall Moran's Index of Logistics Development Level in 2008-2016.

It can be seen that the overall Moran's index fluctuated significantly during this period. The peak value was 0.3382 in 2013, the minimum value was 0.2831 in 2014, and the $Z$ value reflecting the degree of dispersion was greater than 1.96. The $Z$ value reached the maximum value of 3.29 in 2013, and the $P$ value from 2008 to 2016 was less than 0.01 , which passed the spatial significance test of $1 \%$. This shows that the development level of the logistics industry in 31 provinces in China will produce agglomeration effect in space, showing a significant positive correlation. That is to say, areas with the same level of logistics development will more likely agglomerate. This is mainly due to the existence of spatial spillover effect or spatial expansion among regions. From the perspective of time dimension, the overall Moran's index shows a downward trend from 2010 to 2012, 2013 to 2014, and 2015 to 2016, indicating that the spatial correlation of logistics development is gradually weakening during this period; that is, the spatial agglomeration effect is gradually weakening. The Moran's index shows an upward trend in the three stages of 2008-2010, 2012-2013, and 2014-2015, which indicates that the agglomeration effect of the logistics industry is more obvious in this stage. Because of the difference of regional economy development, the differences of supply and demand in different regions are caused, which further affects the agglomeration intensity of the development level of the logistics industry.

\subsection{Local Spatial Agglomeration Characteristics of Logistics Industry Development}

Overall, Moran's index mainly calculates the spatial agglomeration effect of logistics development level in 31 provinces, but it cannot determine the degree of spatial correlation between each province and its surrounding provinces. Therefore, the spatial correlation among provinces should also be analyzed. Through the empirical analysis of Moran index, we can see that there are great differences in different years. Therefore, in order to have a more detailed understanding of its development at different stages, the three years of 2008, 2012, and 2016 are chosen as the time section to analyze on the basis of the principle of average distribution, and uses local Moran's index to analyze the spatial correlation of 31 provinces' logistics comprehensive development level in 2008, 2012, and 2016, and 
estimates the heterogeneity and homogeneity of 31 provinces' logistics comprehensive development level in space. The results are shown in Figures 3-5.

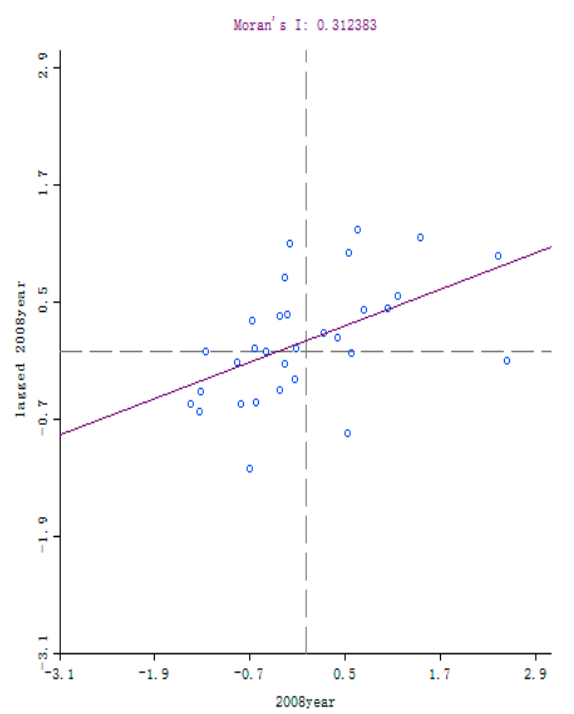

Figure 3. Local Moran's I scatter plot in 2008.

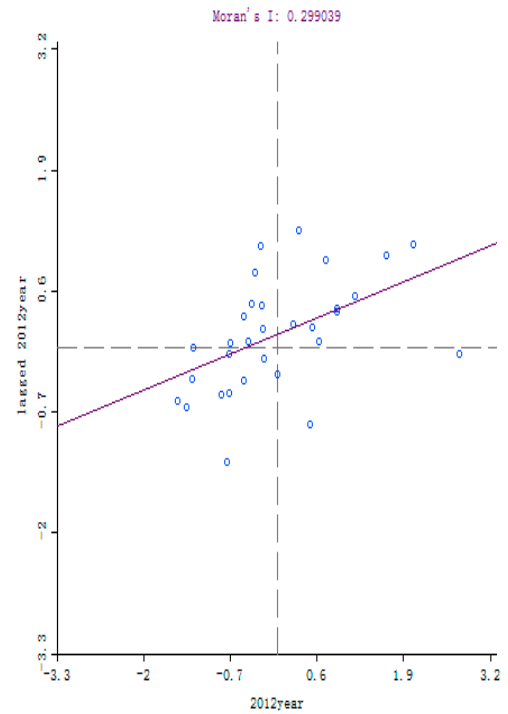

Figure 4. Local Moran's I scatter plot in 2012.

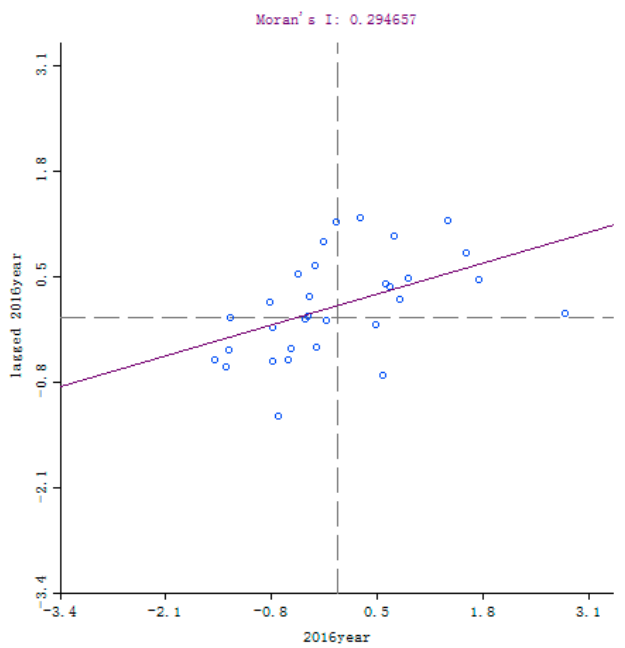

Figure 5. Local Moran's I scatter plot in 2016. 
We can see that in 2008, 2012, and 2016, most scattered points fall in the first quadrant, the second quadrant, and the third quadrant, respectively. These points present three kinds of agglomeration; that is, high-high, low-high, and low-low agglomeration. Only a few provinces are scattered in the fourth quadrant, which is high-low agglomeration. The scattered points fall in the first quadrant and the third quadrant, which indicates that there is a significant positive correlation in the development of the logistics industry in space. The scattered points fall in the second quadrant and the fourth quadrant, which indicates that there is a significant negative correlation in the development level of the logistics industry in space. This is mainly due to the fact that the different levels of development of the logistics industry will have a negative impact among neighboring provinces. From 2008 to 2012, the spatial pattern of logistics development level has changed, and the spatial correlation intensity of some provinces has changed. The number of provinces in the high-high agglomeration mode and the low-high agglomeration mode increased by 1 , while the number of provinces in the low-low agglomeration mode and the high-low agglomeration mode decreased by 1 . From 2012 to 2016, the number of provinces in the high-high agglomeration mode decreased by 1 , the number of provinces in the low-high agglomeration mode decreased by 2 , and the number of provinces in the low-low agglomeration mode increased by 3 , while the number of provinces in the high-low agglomeration mode remained unchanged.

Through scatter plots, we can see that there are four correlative models among 31 provinces, but these spatial correlation analyses cannot explain how the logistics development level of individual provinces affects the adjacent areas. Therefore, with the help of Geoda software, the LISA agglomeration maps of 2008, 2012, and 2016 are drawn to clearly show the change process of provinces in four spatial agglomeration modes, as shown in Figures 6-8.

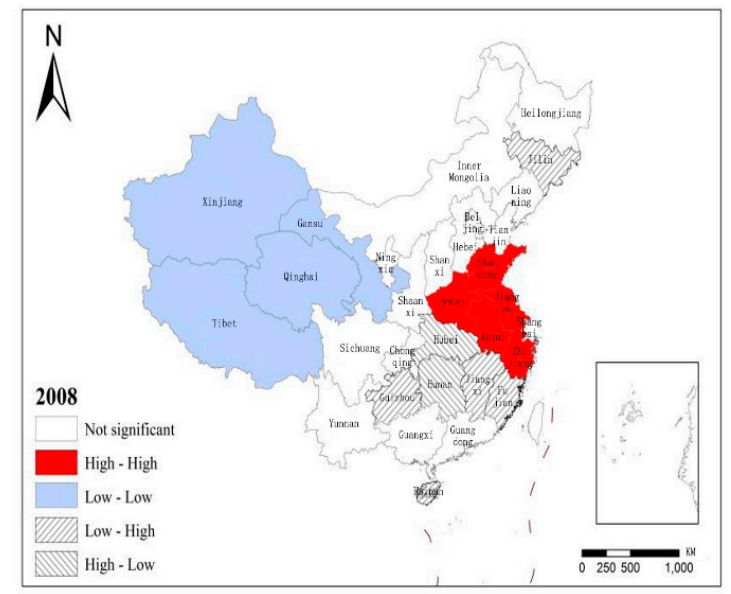

Figure 6. Aggregation graph in 2008 of the logistics industry.

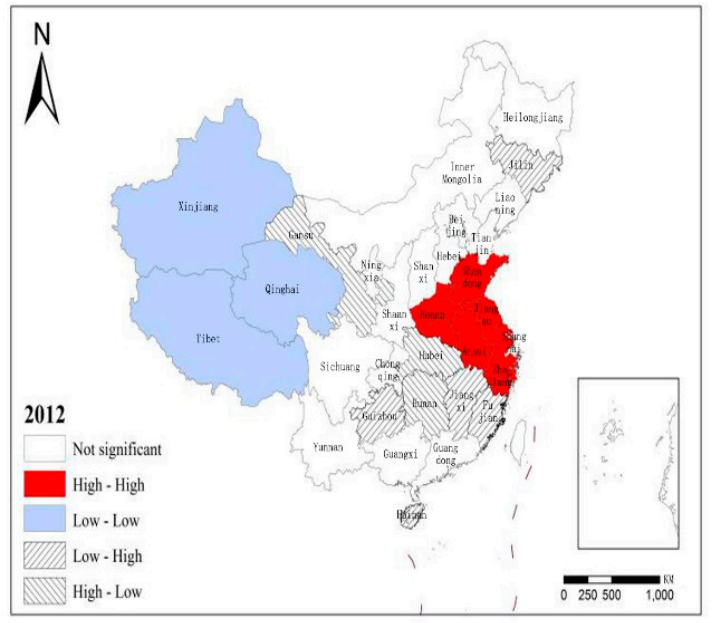

Figure 7. Aggregation graph in 2012 of the logistics industry. 


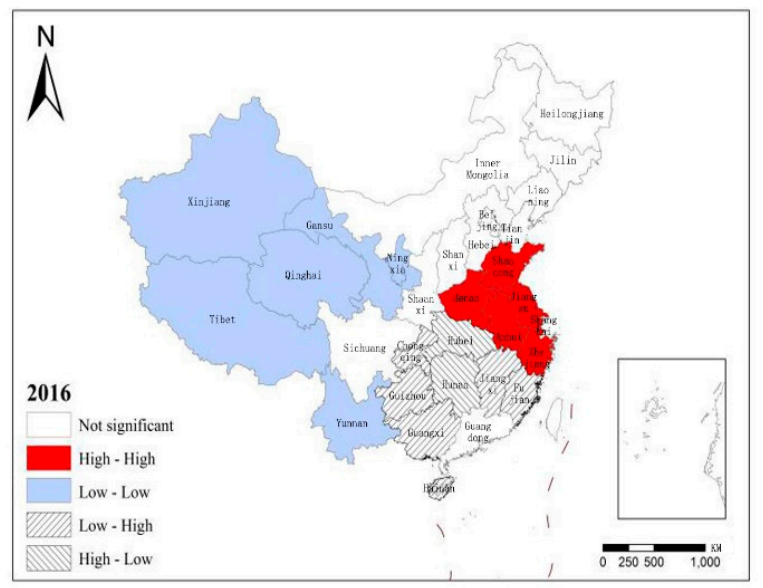

Figure 8. Aggregation graph in 2016 of the logistics industry.

Figure 6 shows that the spatial correlation model of logistics development level in 2008 is mainly high-high, low-high, and low-low, and the provinces with high-high agglomeration are mainly located in the Central and Eastern regions. The Central region includes Henan, and the Eastern region includes Shandong, Jiangsu, Anhui, and Zhejiang. The provinces with low-high concentration are Hubei, Hunan, Guizhou, Jiangxi, Fujian, and Jilin. The low-low agglomeration pattern is located in the Western region, which mainly includes Xinjiang, Tibet, Qinghai, and Gansu. In 2012, Shanghai in the Eastern region joined the high-high agglomeration area, and Gansu in the Western region joined the low-high agglomeration area. This shows that the development speed of Shanghai's logistics industry is higher than that of neighboring provinces, and the gap is gradually decreasing, while Gansu's logistics development speed is lower than that of neighboring provinces, and this is gradually increasing. In 2016, Shanghai in the Eastern region dropped out of the high-high agglomeration area because of the lower development speed of the logistics industry than the surrounding provinces, while Gansu and Yunnan entered into the low-low agglomeration area, and Jilin exited the low-high agglomeration area. The spatial correlation of Jilin is not significant, which is mainly because the spatial spillover effect of the development level of the logistics industry in Jilin on the surrounding provinces is not obvious. In 2016, there is a negative spatial correlation between Chongqing's logistics industry and the surrounding provinces, which reflects the spatial heterogeneity.

\section{Econometric Analysis of Influencing Factors of Spatial Relations in the Logistics Industry}

\subsection{Influence Factor}

In the process of selecting the influencing factors affecting the spatial correlation of the logistics industry and their degree of influence, the principle of data accessibility and data synthesis is followed. The main influencing factors are the macro-level indicators of the logistics industry. However, some micro-level factors, such as the impact of different types of enterprises' demand for regional logistics cooperation, which can cause the spatial relations of logistics industry, will not be discussed in this paper because the difficulty of obtaining data. This paper chooses indicators as influencing factors from the following four aspects to explore how they affect the development of logistics industry. These factors include:

(i) Logistics infrastructure factors. The development of the logistics industry is based on the establishment of facilities. Infrastructure, such as roads and railways, has become the key channel for regulating material supply and demand. By using these infrastructures to develop multimode transport, we can not only promote the cooperation of various modes of transport and strengthen the cooperation of different departments, but also coordinate the use of inter-regional infrastructures and improve the quality of logistics. Therefore, this paper chooses the total mileage $(\mathrm{km})$ of railways, 
highways, and inland waterways as the length of the transport line, representing the level of traffic development, and using LOGVALUE to express this.

(ii) Economic development factors. The development of the logistics industry can effectively promote the development of the regional economy, and vice versa. The rapid growth of the economic level can effectively stimulate the residents to improve their quality of life, thus stimulating the potential demand for material goods. The increase of goods demand can further lead to the development of the logistics industry. In order to better reflect the economic development, some scholars used the GDP of each province to represent the economic development of the province [18]. However, using GDP as a measure index cannot exclude the impact of population. Therefore, this paper uses per capita GDP (yuan) as an explanatory variable to represent the economic growth of the region, and uses PERGDP to express this.

(iii) Information factors. The development of the logistics industry cannot be separated from the support of logistics information technology and information platform. With consumers' consumption habits now relying on the Internet and various transportation and distribution technologies, more people choose to meet their daily needs by online shopping. Therefore, this paper uses express business volume (10,000 pieces) as an explanatory variable to measure the degree of information development, expressed by INFRAS. Based on the surge of express business in 2012, in order to understand more clearly the impact of information factors on the development of the logistics industry, this paper takes 2011 as the time line to study the impact of the index on the development of the logistics industry from 2008 to 2011, and 2012 to 2016.

(iv) Human resource factors. Human resource is considered to be the key indicator of value creation so far. Appropriate allocation of human resources can effectively promote the development of the logistics industry. Therefore, this paper takes the number of persons employed in transportation, warehousing, and the postal industry as the index to measure the human resource factors, and uses HR to express this.

\subsection{Selection of Spatial Econometric Model}

Spatial lag model (SLM) and spatial error model (SEM) are applied to analyze the influencing factors of spatial relationship in the logistics industry in this paper. The contents of the two models are as follows.

(i) Spatial lag model. Spatial lag model is a method to reflect whether there exists diffusion or spillover phenomenon in the spatial dimension of each province; that is, whether the development of the logistics industry is affected not only by the relevant factors in this region, but also by the development of logistics industry in neighboring provinces. The model is represented as:

$$
y=\gamma+\rho W y+x \beta_{1}+\varepsilon_{1}
$$

where $y$ is the dependent variable, that is, the interpreted variable; $\gamma$ is a constant, $\rho$ is a spatial regression coefficient, which reflects the spatial dependence of sample observations. If $\rho$ is more significant, it means that the development level of the logistics industry does depend on each other in space. The value of $\rho$ can effectively measure the spatial impact of the development of the logistics industry in neighboring provinces on the development of logistics and the direction of impact. $W$ is the spatial weight matrix, $W_{y}$ is the spatial lag dependent variable, which indicates the extent of the influence of the explained variables due to the spatial distance. In this paper, it shows the degree of spatial spillover of the development level of the logistics industry to the neighboring provinces. $\beta_{1}$ represents the coefficient and $\varepsilon_{1}$ represents the variable of random error term. If the logistics industry has significant spatial correlation and has an impact on the logistics industry of neighboring provinces, the model can be used for analysis.

(ii) Spatial error model. The error term is introduced into the spatial error model, which indicates that the error term is spatially correlated. The form of the model is as follows: 


$$
\begin{gathered}
\mathrm{y}=\gamma+x \beta+\varepsilon \\
\varepsilon=\lambda W_{1}+\varphi
\end{gathered}
$$

where $\lambda$ represents the spatial error coefficient, which means that there may be some factors that cause the spatial correlation between the error items; $\varphi$ is a random variable, which obeys $N\left(0, \sigma^{2}\right)$. When some neglected variables, i.e., error items, have spatial correlation with the development of the logistics industry in neighboring provinces, the model can be used.

After three steps of multi-collinearity test, heteroscedasticity test, and model selection, the fixed effect of spatial error model (SEM-FE) is finally selected to carry out empirical analysis in this paper.

\subsection{Analysis of Empirical Results}

Stata software was used to explore the impact of logistics infrastructure factors, economic development factors, information factors, and human resource factors on the development level of the logistics industry from 2008 to 2011, and 2012 to 2016. The final estimate results are shown in Table 5.

\begin{tabular}{|c|c|c|c|}
\hline & & $2008-2011$ & 2012-2016 \\
\hline & & SEM-FE & SEM-FE \\
\hline \multirow{16}{*}{$\begin{array}{l}\text { Main Spatial } \\
\text { Variance }\end{array}$} & \multirow{2}{*}{ LOGVALUE } & 0.265 & 0.294 \\
\hline & & $(11.40)^{* * *}$ & $(11.01)^{* * *}$ \\
\hline & \multirow[t]{2}{*}{ PERGDP } & 0.287 & 0.3019 \\
\hline & & $(5.50)^{* * *}$ & $(5.03) * * *$ \\
\hline & \multirow[t]{2}{*}{ INFRAS } & 0.2584 & 0.3568 \\
\hline & & $(8.71)^{* * *}$ & $(5.71) * * *$ \\
\hline & \multirow[t]{2}{*}{ HR } & 0.1004 & 0.0851 \\
\hline & & $(5.54) * * *$ & $(3.67) * * *$ \\
\hline & \multirow[t]{2}{*}{ cons } & 0.1436 & 0.1579 \\
\hline & & $(12.23)^{* * *}$ & $(18.66)^{* * *}$ \\
\hline & \multirow[t]{2}{*}{ lambda } & 0.0008 & 0.0012 \\
\hline & & $(8.53)^{* * *}$ & $(10.35)^{* * *}$ \\
\hline & \multirow[t]{2}{*}{ ln_phi } & 0.3784 & 0.0343 \\
\hline & & $(11.46)^{* *}$ & $(2.13)^{* * *}$ \\
\hline & \multirow[t]{2}{*}{ sigma2_e } & 0.0013 & 0.0017 \\
\hline & & $(7.35)^{* * *}$ & $(7.55) * * *$ \\
\hline \multicolumn{2}{|l|}{$\mathrm{R}^{2}$} & 0.73 & 0.66 \\
\hline \multicolumn{2}{|l|}{$\mathrm{N}$} & 124 & 155 \\
\hline
\end{tabular}

Table 5. Measurement results of spatial influencing factor.

In Table 5, Cons represents the constants in the spatial error model, Lambda is the spatial correlation coefficient, and ln_phi is a spatial error coefficient, which indicates the influence of the variation of error terms on neighboring regions. Sigma2_e is the variance of the effective estimator, that is, the variance effective estimator of 31 provinces in a fixed period of time. $R^{2}$ is used as goodness of regression line to the comprehensive development level of logistics. Table 5 shows that the values in different time periods are greater than 0.6 , which indicates that the goodness of fit is better. $\mathrm{N}$ is the total number of counts.

Table 5 shows that from 2008 to 2011, the impact degree of each index on logistics industry from big to small is: per capita GDP, transport line length, express business volume, and number of employees. From 2012 to 2016, the order is transformed into: express business volume, per capita GDP, transport line length, and number of employees. Although the effects of various factors are different, and the spillover or diffusion effects of economic factors, information factors, and traffic factors are 
enhanced, while the effects of human resource factors are weakened, from the overall perspective, the spillover or diffusion effects of logistics industry development in space are significantly enhanced.

The length of the traffic line is positively correlated with the development level of the logistics industry at 0.01 level, which is consistent with expectations. Before 2011, the development level of the logistics industry will increase by 0.265 units for every additional unit of traffic line length. From 2012 to 2016, the development level of the logistics industry will increase by 0.294 units for every additional unit of traffic line length, and the degree of influence gets increased. Transportation, as the core functional element of logistics, is the necessary condition to complete production, processing, manufacturing, and sales. In recent years, the government and social enterprises have invested a lot of capital to support the construction of highways and railways, which makes the scale of the existing road network gradually coordinate with the speed of social and economic development. By improving the use of equipment, re-planning system construction, transportation capacity, and quality of transport services have been improved. Encouraging the sharing of resources between the government and enterprises, so that the government and enterprises have more channels to obtain transport resources, effectively meets the multi-level market transport needs.

Per capita GDP and the level of development of the logistics industry have a significant positive correlation at 0.01 level, which is consistent with expectations. Before 2011, the development level of the logistics industry increased by 0.287 units for every unit of per capita GDP increase. From 2012 to 2016, the development level of the logistics industry increased by 0.3019 units for every unit of per capita GDP increase. This factor has a relatively increased impact on logistics. In recent years, the government has strongly supported the strategy of developing the western region and promoted the "one belt and one way" to effectively improve the transportation problem. The economic level in the western region has improved, which stimulates people to have higher demand, thus increasing the demand for logistics.

There is a positive correlation between express business volume and logistics development level at 0.01 level, which is in line with expectations. Before 2011, the development level of the logistics industry increased by 0.2584 units for each additional unit of express business volume. From 2012 to 2016, the development level of logistics industry increased by 0.3568 units for each additional unit of express business volume, and its influence increased. Since 2012, several large private enterprise giants have formed strategic alliances to undertake most of the express business in the Chinese market. In recent years, with the deepening of foreign trade and the popularity of the Internet, the government and enterprises attach great importance to the research and development and application of information technology. Information technology has become the dominant support force in the logistics development. Especially after 2012, Geographic Information System (GIS) system, Global Positioning System (GPS) system, sensing technology, bar code technology, databasing, EDI, and other technologies have been applied efficiently and safely, which has led to modern logistics networks, automation, or even intellectualization.

The number of employed persons in the logistics industry is positively correlated with the development level of the logistics industry at 0.01 level, which is consistent with expectations. Before 2011, the development level of the logistics industry increased by 0.1004 units for each additional employee unit. From 2012 to 2016, the development level of logistics industry increased by 0.0851 units for each additional employee unit, and the impact was relatively reduced. With the development of express delivery in the logistics industry in recent years, the problem of labor shortage has arisen. In order to seize market share, some logistics enterprises recruit a large number of logistics operators and distributors. Neglecting the promotion of employees' skills led to the decline of logistics development level.

\section{Conclusions and Implications}

This study evaluates the development level of the logistics industry in 31 provinces of China by using the method of entropy weight. On this basis, Moran'I index, Moran'I scatter plot, and LISA 
agglomeration plot are used to analyze the overall and local spatial agglomeration characteristics of logistics industry development. Four main factors affecting the spatial relationship of the logistics industry are analyzed by choosing the fixed effect of the spatial error model. The empirical study yields the following three conclusions.

(i) There is spatial agglomeration effect in the development level of the logistics industry from the overall perspective. The results show that the level of logistics development in 31 provinces in China will produce agglomeration effect in space, showing a significant positive correlation; that is, areas with the same level of logistics development will more likely agglomerate. This is mainly due to the existence of spatial spillover effect or spatial diffusion effect between regions. However, the level of agglomeration varies greatly in different time periods. The overall Moran's I index shows a downward trend from 2010 to 2012, from 2013 to 2014, and from 2015 to 2016, which indicates that the spatial correlation of logistics development is gradually weakening during these periods; that is, the spatial agglomeration effect is gradually weakening. However, the Moran's I index shows an upward trend in the three stages of 2008-2010, 2012-2013, and 2014-2015, which indicates that the agglomeration effect of the logistics industry is more obvious in these periods.

(ii) Regional differentiation of spatial agglomeration effect is obvious from the local perspective. Most of the provinces in the high-high agglomeration area are located in the Central and Eastern region, while most of the provinces in the Western region are in the low-low agglomeration area. It shows that the cooperation ability and mechanism between provinces in the Central and Eastern region are better than those in the Western region. Provinces in the Eastern region have the advantages of location, facilities, and talent, which are more conducive to the development of the agglomeration effect, while in the western region, it lacks these advantages.

(iii) The influence of human resource factors on the spatial relationship of logistics development level is declining. Among all the influencing factors, information factors play a more significant role. At the same time, the impact of human resources factors is declining. This shows that the express delivery industry and information technology will play an increasingly important role in the development of the logistics industry, while the development of the logistics industry cannot be supported only by the expansion of personnel scale.

There are three implications as follows: (i) The spatial correlation of the logistics industry makes it necessary to strengthen logistics cooperation among regions, which mean that the development of interregional collaborative logistics activities should be encouraged. From a macroscopic perspective, the government must treat the spatial linkage of the logistics industry as an important decision variable in policy formulation and make full use of this relationship. From a microscopic perspective, all logistics organizations, including logistics industry associations, logistics enterprises, and logistics departments within enterprises, should be active and promote innovation cooperation among different regions. (ii) It can be seen that the relationship between the logistics industry and the sustainable development of regional economies is becoming closer to the empirical results. On the one hand, the agglomeration of the logistics industry can effectively improve the operational efficiency of the logistics industry, strengthen the service level, and better provide sufficient impetus for regional economic development. On the other hand, the development of regional economies further promotes the spatial relationship of the logistics industry. With the increase of all kinds of resources needed for regional economic development, the spatial relationship of logistics will also be strengthened, thus further promoting the agglomeration of the logistics industry. (iii) With the increase of interregional logistics activities, the impact on the environment will also increase. For example, increasing fuel consumption, aggravating air pollution and waste pollution, wasting resources, and causing urban traffic congestion will have a negative impact on the sustainable development of the social economy. Therefore, we should try our best to eliminate these negative effects, while giving full attention to its role in the process of logistics industry development.

Our research also has some limitations. First and most notably, our results are based on data for China. We reason that the results are correct based on the empirical test above and are in line with 
China's national condition. However, they are not widely applicable to other regions because of the different situation of each region. Therefore, we could expand the scope of the research by conducting a comparative study of the logistics industry in another country, in which we would study the spatial correlation according to the logistics industry characteristics of different regions. At the same time, four factors are selected as the factors affecting the spatial relationship of the logistics industry in this paper. However, some factors that may have spatial effects are not taken into account. In future studies, these factors should be considered more comprehensively in order to explain the spatial relationship of the logistics industry more scientifically.

Author Contributions: X.T. wrote the paper. M.Z. contributed to the collection of data and ideas.

Funding: This research was funded by Soft Science Research Project in Shanxi Province of China, No. 2016041003-1.

Acknowledgments: We gratefully acknowledge the support of Soft Science Research Project in Shanxi Province of China. The authors also wish to express their sincere thanks to the editors for their work on the paper.

Conflicts of Interest: The authors declare no conflicts of interest.

\section{References}

1. National Bureau of Statistics of China. China Statistical Yearbook in 2002; National Bureau of Statistics of China: Beijing, China, 2002.

2. National Bureau of Statistics of China. China Statistical Yearbook in 2017; National Bureau of Statistics of China: Beijing, China, 2017.

3. Yeo, G.T.; Roe, M.; Dinwoodie, J. Measuring the competitiveness of container ports: logistician's perspectives. Eur. J. Mar. 2011, 45, 455-470. [CrossRef]

4. Mothilals, G.A.; Nachiappan, S.P. Key success factors and their performance implications in the Indian third-party logistics (3PL) industry. Int. J. Prod. Res. 2012, 50, 2407-2422. [CrossRef]

5. Tang, J.R.; Wang, X.X. Spatio-temporal Evolution of China's Logistics Industry Efficiency. J. Beijing. Jiaotong Univ. (Soc. Sci. Ed.) 2016, 1, 122-127.

6. Sun, Q.L.; Chen, H.X. Evaluation of logistics competitiveness of some nodes cities along "One belt and One road". Railw. Tran. Ecol. 2016, 9, 25-29.

7. Chen, H.; Wei, X.J.; Du, Q. Dynamic track evolution of factors driving the development of logistics industry in the "One belt and One Road" regions: From the perspective of labor input. J. Shanghai Univ Fina. Econ. 2015, 2, 31-43.

8. Nie, Z.Y.; Li, S. Quantile regression analysis of difference in the effects of logistics industry upon regional economic growth. J. Ind. Tech. Econ. 2015, 10, 77-82.

9. Zhang, X.Q. The study on the coordinated development of the regional logistics in the "One belt and One road" regions. Stat. Deci. 2016, 8, 108-110.

10. Wang, W.M.; Gao, Y.Y. Evaluation and suggestions on logistics competitiveness of inland cities with "One belt and One road". J. Comm. Ecol. 2016, 4, 92-93.

11. Song, L.; Zuo, X.M. Empirical study on regional logistics competitiveness based on factor analysis. J. Southwest China Norm. Univ. 2017, 7, 163-167.

12. Zhao, J.Y. Fuzzy approximation ideal ranking model for competitiveness of multi-regional logistics industry. J. Zhejiang Univ. 2015, 4, 413-418.

13. Guo, Z.X.; Wang, L.Y. Evaluation of logistics industry competitiveness in Hebei Province based on combination empowerment-TOPSIS. J. Hebei Univ. 2017, 1, 121-130.

14. Sun, X. Study on the Logistics Efficiency of Three Northeast Provinces Based on Three-Stage DEA; Springer: Berlin/Heidelberg, Germany, 2012.

15. Markovits-somogyi, R. Assessing the logistics efficiency of European countries by using the DEA-PC methodology. Transport 2014, 2, 137-145. [CrossRef]

16. Chen, Y.P.; Zhang, L.L. Regional convergence: Efficiency and convergence of China's logistics industry: A study based on panel data of 31 provinces from 2006 to 2015. J. Bus. Econ. 2018, 3, 5-19.

17. Fan, Y.J. Temporal and spatial changes and influencing factors of logistics industry efficiency in national circulation node cities. China Busi. Mark. 2015, 11, 1-8. 
18. Dablanc, L.; Rakotonarivo, D. The impacts of logistics sprawl: How does the location of parcel transport terminals affect the energy efficiency of goods' movements in Paris and what can we do about it? Procedia Soc. Behav. Sci. 2010, 3, 6087-6096. [CrossRef]

19. Hesse, M.; Rodrigue, J.P. The transport geography of logistics and freight distribution. J. Transp. Geogr. 2004, 3, 171-184. [CrossRef]

20. McKinnon, A. The present and future land requirements of logistical activities. Land Use Policy 2009, 26, 293-301. [CrossRef]

21. Allen, J.; Browne, M.; Cherrett, T. Investigating relationships between road freight transport, facility location, logistics management and urban form. J. Transp. Geogr. 2012, 24, 45-57. [CrossRef]

22. Sakai, T.; Kawamura, K.; Hyodo, T. Spatial reorganization of urban logistics system and its impacts: Case of Tokyo. J. Transp. Geogr. 2017, 60, 110-118. [CrossRef]

23. Dablanc, L.; Ross, C. Atlanta: A mega logistics center in the piedmont Atlantic megaregion. J. Transp. Geogr. 2012, 24, 432-442. [CrossRef]

24. Cidell, J. Concentration and decentralization: The new geography of freight distribution in US metropolitan areas. J. Transp. Geogr. 2010, 18, 363-371. [CrossRef]

25. John, T.; Bowen, J. Moving places: The geography of warehousing in the US. J. Transp. Geogr. 2008, 16, 379-387.

26. Zhang, L.L.; Zhao, J.L.; Song, J.P. Research on evolution of logistics enterprise spatial pattern and influencing factors in Beijing-Tianjin-Hebei urban agglomeration. Econ. Geogr. 2019, 1, 1-12.

27. Li, G.Q.; Jin, F.J.; Chen, Y. Spatial patial patterns of logistics industry based on a geographic analysis of hotness degree. Progress Geogr. 2015, 5, 629-637.

28. Wang, C.J.; Zhang, M.T. Spatial pattern and its mechanism of modern logistics companies in China. Progress Geogr. 2014, 1, 134-144.

29. Wang, C.J.; Li, G.Q. Entrance of international logistics firms into mainland China and its spatial network. Hum. Geogr. 2016, 4, 72-79.

30. Shen, Y.F.; Wang, N.Z.; Ma, R.F. Research on the spatial distribution of regional logistics and evolution in the Yangtze River delta. Econ. Geogr. 2011, 4, 618-623.

31. Chen, Y.; Long, Y.; Xu, C.L. Study on spatial difference of logistics industry relevance degree in Yangtze River economic belt. World Geogr. Res. 2013, 1, 73-82.

32. Jing, N.; Yan, B. Spatial Autocorrelation and Cluster Analysis of Logistics and Economy in Northeast China. J. Northeast Norm. Univ. 2015, 1, 134-141. 